Subscriber access provided by Caltech Library

\title{
Communication
}

\section{Explanation of Dramatic pH-Dependence of Hydrogen Binding on Noble Metal Electrode: Greatly Weakened Water Adsorption at High pH.}

\author{
Tao Cheng, Lu Wang, Boris V. Merinov, and William A. Goddard
}

J. Am. Chem. Soc., Just Accepted Manuscript • DOI: 10.1021/jacs.8b04006 • Publication Date (Web): 24 May 2018

Downloaded from http://pubs.acs.org on May 24, 2018

\section{Just Accepted}

"Just Accepted" manuscripts have been peer-reviewed and accepted for publication. They are posted online prior to technical editing, formatting for publication and author proofing. The American Chemical Society provides "Just Accepted" as a service to the research community to expedite the dissemination of scientific material as soon as possible after acceptance. "Just Accepted" manuscripts appear in full in PDF format accompanied by an HTML abstract. "Just Accepted" manuscripts have been fully peer reviewed, but should not be considered the official version of record. They are citable by the Digital Object Identifier (DOI®). "Just Accepted" is an optional service offered to authors. Therefore, the "Just Accepted" Web site may not include all articles that will be published in the journal. After a manuscript is technically edited and formatted, it will be removed from the "Just Accepted" Web site and published as an ASAP article. Note that technical editing may introduce minor changes to the manuscript text and/or graphics which could affect content, and all legal disclaimers and ethical guidelines that apply to the journal pertain. ACS cannot be held responsible for errors or consequences arising from the use of information contained in these "Just Accepted" manuscripts. 
Despite the broad application of hydrogen oxidation reaction (HOR) and hydrogen evolution reactions (HER) in electrochemical catalysis, ${ }^{1-2}$ for yet unclear reasons the HOR/HER kinetics on noble metals are much slower in alkaline than in acid electrolytes, ${ }^{3}$ which poses enormous challenges in practical applications. For example, the HOR/HER reaction rate is as two orders of magnitude slower in strong base than that in strong acid, ${ }^{3}$ which significantly diminishes the overall performance of oxygen reduction reaction $(\mathrm{ORR})^{4}$ and the oxygen evolution reaction (OER) in alkaline electrolyte. ${ }^{5-6}$

The slow HER rate in base than in acid has been rationalized as arising from the faster formation of $\mathrm{H}_{\mathrm{ad}}$ from $\mathrm{H}^{+}$than from $\mathrm{H}_{2} \mathrm{O},{ }^{7-8}$ or in terms of the change in configurational entropy of the proton. ${ }^{9}$ However, none of these explanations are entirely satisfactory, considering that in $\mathrm{HOR} \mathrm{H}_{\mathrm{ad}}$ forms from $\mathrm{H}_{2}$ dissociation without involving $\mathrm{H}^{+}$, but still the activity decreases significantly from acid to base conditions, and lower activation energy is observed for HOR/HER in acid than in base. ${ }^{10-11}$ Instead, the $\mathrm{pH}$-dependent hydrogen binding energy (HBE), derived from cyclic voltamme-

try $(\mathrm{CV})$, is considered to be a more reliable descriptor. For example, Shen et al. observed a $0.15 \mathrm{eV}$ increase in the HBE as the $\mathrm{pH}$ is increased by 13 units, which in turn changes the HOR/HER activity by two orders of magnitude. ${ }^{12}$ However, the underlying cause of this $\mathrm{pH}$-dependent behavior is still far from clear.

The HBE $\left(\Delta G_{H}^{a d}\right)$ is typically considered as an intrinsic property of each metal with no $\mathrm{pH}$ dependence. ${ }^{13}$

$$
\begin{gathered}
\frac{1}{2} \mathrm{H}_{2}+\mathrm{M} \rightarrow \mathrm{M}-\mathrm{H}_{a d} \\
\Delta G_{H}^{a d}=\Delta G_{\mathrm{M}-\mathrm{H}_{\mathrm{ad}}}-\left(\Delta G_{1 / 2 \mathrm{H}_{2}}+\Delta G_{\mathrm{M}}\right)
\end{gathered}
$$

However, the electrode surface in an aqueous electrolyte is known to be covered with water, and thus it is likely that the adsorption/desorption of hydrogen is accompanied by desorption/re-adsorption of water, ${ }^{14}$

$$
\begin{gathered}
\frac{1}{2} \mathrm{H}_{2}+\mathrm{M}-\mathrm{H}_{2} \mathrm{O} \rightarrow \mathrm{M}-\mathrm{H}_{a d}+\mathrm{H}_{2} \mathrm{O} \\
\Delta G_{H}^{a d^{*}}=\Delta G_{\mathrm{M}-\mathrm{H}_{\mathrm{ad}}}-\left(\Delta G_{1 / 2 \mathrm{H}_{2}}+\Delta G_{\mathrm{M}-\mathrm{H}_{2} \mathrm{O}}-\Delta G_{\mathrm{H}_{2} \mathrm{O}}\right)
\end{gathered}
$$

Therefore, it is rational to expect that the apparent hydrogen binding energy (HBE*, $\Delta G_{H}^{a d^{*}}$ ), taking into account both the intrinsic $\mathrm{HBE}$ and the water adsorption energy, exhibits a $\mathrm{pH}$ dependent behavior. ${ }^{14}$ Furthermore, one should notice that the same values of Us at different $\mathrm{pH}$ in the RHE scale are actually different in the SHE scale. Very possibly, the variations in Us (hereafter, all the Us are for the SHE scale unless otherwise specified) lead to the changes in water adsorption, which in turn modifies the hydrogen adsorption. Therefore, we suspect that water adsorption at different $\mathrm{Us}$ are the underlying cause of $\mathrm{pH}$ dependent $\mathrm{HBE}^{*}$.

To prove this hypothesis, we need to answer two fundamental questions:

- $\quad$ First, what are the influences of different Us to water adsorption?

- Second, what are the influences of water adsorption to $\mathrm{HBE}^{*}$ ?

To answer the first question, we carried out QMMD with explicit solvent to directly simulate water/Pt (100) interface. We 
considered $\mathrm{U}$ between $+0.29 \mathrm{~V}$ to $-0.46 \mathrm{~V}$ to cover the range of experimental condition from $\mathrm{pH} 0.2$ to 12.8 at $\mathrm{U}=+0.3 \mathrm{~V}$ (RHE). The work function of water/Pt (100) predicted from QM-MD is $5.06 \mathrm{eV}$, which corresponding to $\mathrm{U}=0.62 \mathrm{~V}$ (taking reference SHE as $-4.44 \mathrm{eV}$ ), close to the experimental potential of zero charge (PZC) on Pt (100) of $0.41 \mathrm{~V}^{15}$ Extra electrons were introduced to simulate more negative $\mathrm{U}$, which can be achieved by either explicitly introducing sodium $(\mathrm{Na}$ ) (as shown in Figure 1b) or combining an implicit solvation model ${ }^{16}$ on top of explicit water leading to the hybrid scheme(as shown in Figure 1c). The advantage of the hybrid scheme is that we can continuously control the work function by introducing fractional charges at explicit/implicit interface under Poisson-Boltzmann approximation. ${ }^{16}$ For example, we can simulate the work function of $4.73 \mathrm{eV}, 4.34$ $\mathrm{eV}, 4.11 \mathrm{eV}$ and $3.98 \mathrm{eV}$ by introducing extra charges of $0.97 e^{-}$, $1.94 e^{-}, 3.06 e^{-}$and $3.48 e^{-}$, resulting in $\mathrm{U}=+0.29 \mathrm{~V},-0.10 \mathrm{~V}$, $0.33 \mathrm{~V}$ and $-0.46 \mathrm{~V}$. Thus, with both the explicit and hybrid scheme, we can carry out QMMD simulations and perform in situ analysis at given $\mathrm{Us}$ of $\mathrm{H}_{\mathrm{UPD}}$ from $\mathrm{pH} 0.2$ to 12.8 .

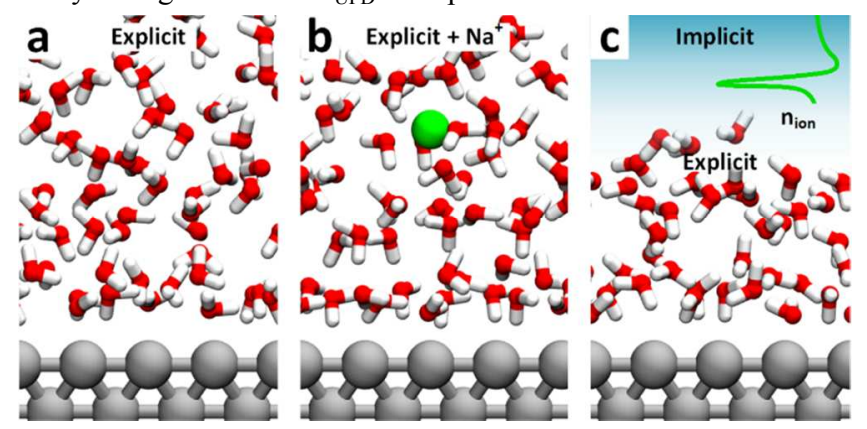

Figure.1 The water/Pt (100) interface in QMMD simulations. (a) Explicit model ( $\sim 6$ water layers) (b) Explicit $+\mathrm{Na}^{+}$model $(\sim 6$ water layers $+1 \mathrm{Na})$ and (c) Explicit + Implicit model $(\sim 3$ water layers + Implicit solvation model). The colors are $\mathrm{Pt}$ in silver, $\mathrm{O}$ in red, $\mathrm{H}$ in white and $\mathrm{Na}$ in green.

From $\mathrm{U}=0.29 \mathrm{~V}$ to $-0.46 \mathrm{~V}$, we observed substantial changes in the water adsorption, which is reflected in the distribution of water along the $\mathrm{z}$-axis (perpendicular to the surface). Figure 2a shows the distribution of water perpendicular to the surface along the z-axis (ZDF), in which the first peak of Pt-O is $2.15 \AA$, only $0.13 \AA$ longer than estimated Pt-O valence bond of $2.02 \AA .^{17-18}$ Thus we suspected that the water molecules within the first peak might present chemisorbed characters as observed by Schwarz et al. ${ }^{19}$ As U decreases, the height of the first peak of Pt-O decreases, which demonstrates that the electrode with increasing $d$-electrons tends to repel water, thus, weaken water adsorption.

The weaker Pt-water interaction causes notable reorganization of water in the first layer. Figure $2 \mathrm{f}$ shows a snapshot of water $/ \mathrm{Pt}$ (100) interface at $U=0.29 \mathrm{~V}$. We highlighted the first layer of water in the blue transparent region by plotting the vdW surface. We characterize the orientation of water molecule by measuring the angle $(\theta)$ between water plane and xy plane as shown in Figure 2c. According to $\theta$, we distinguish water molecules with $\theta<$ $30^{\circ}$ or $\theta>150^{\circ}$ as water parallel to the surface $\left(\mathrm{H}_{2} \mathrm{O}^{-}\right.$) (although it is not perfectly parallel to the surface). We distinguish water molecules with $\theta=90^{\circ}$ as water perpendicular to the surface $\left(\mathrm{H}_{2} \mathrm{O}^{\perp}\right)$. As shown in Figure $3 \mathrm{~d}, \mathrm{H}_{2} \mathrm{O}^{=}$is closer to $\mathrm{Pt}$ and contributes to the first Pt-O peak. At $\mathrm{U}=0.29 \mathrm{~V}$, we find $3 \mathrm{H}_{2} \mathrm{O}^{=}$as shown in Figure $2 \mathrm{~d}$ and $2 \mathrm{f}$ (as further confirmed from the distribution of water along z-direction as shown in Figure 2b). Thus, the decrease in the first peak of $\mathrm{Pt}-\mathrm{O}$ radial distribution function (RDF) results from the loss of $\mathrm{H}_{2} \mathrm{O}^{=}$. Figure $2 \mathrm{~g}$ shows the snapshot of water/Pt (100) interface at $\mathrm{U}=-0.46 \mathrm{~V}(\mathrm{pH}=12.8)$. In this case, only one $\mathrm{H}_{2} \mathrm{O}^{=}$is observed (as further confirmed from Figure $2 \mathrm{~b}$ and $2 \mathrm{e}$ ). Thus, at more negative Us the electron-rich Pt surface both repels the water and reorients $\mathrm{H}_{2} \mathrm{O}^{=}$. At even more negative $\mathrm{U}$ (such as -0.90 V), all the $\mathrm{H}_{2} \mathrm{O}^{=}$disappear, with the only $\mathrm{H}_{2} \mathrm{O}^{\perp}$ observed (as shown in Figure S4).
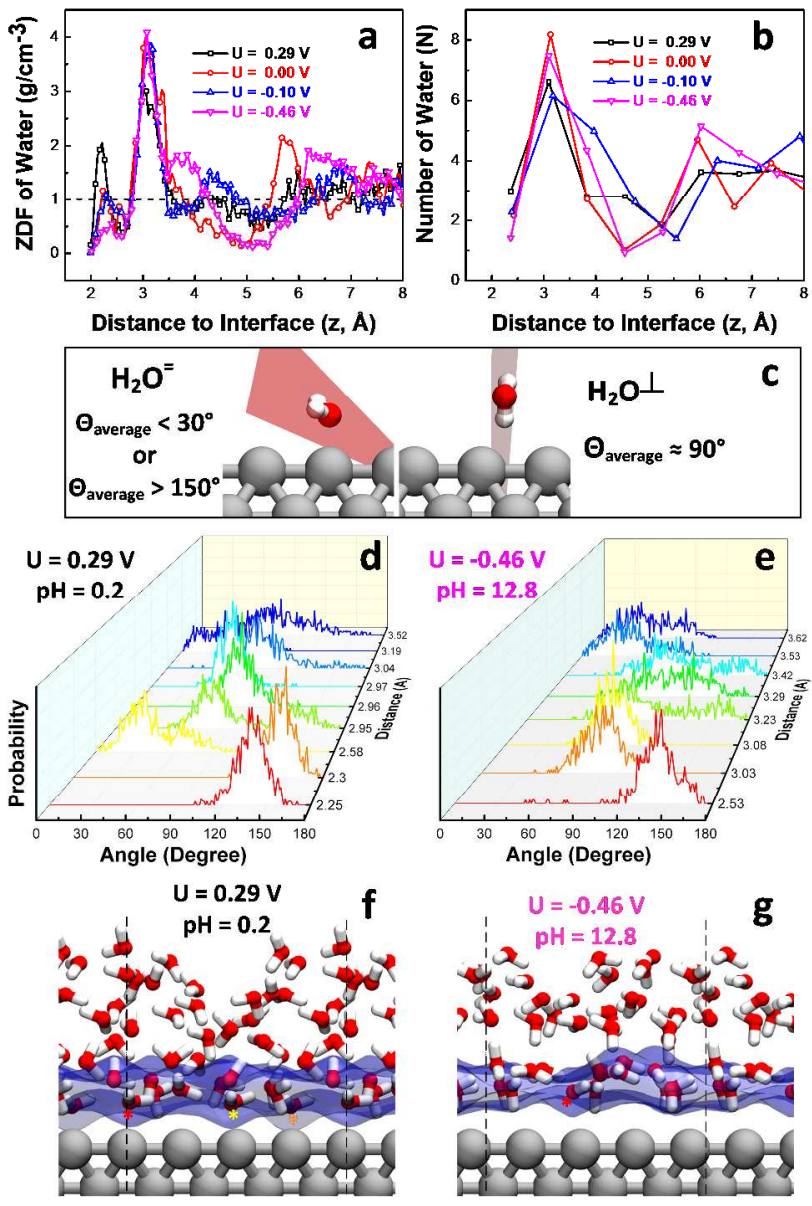

Figure. 2 The interface structures of water adsorption layers under different applied potentials from $+0.29 \mathrm{~V}$ to $-0.46 \mathrm{~V}$. (a) the distribution of water perpendicular to the surface along the $\mathrm{z}$-axis (ZDF) and (b) the number of water (by dividing the interface water from $2 \AA$ to $8 \AA$ into 8 slices). (c) Orientation of water molecules [the angles $(\theta \mathrm{s})$ between water plane and xy plane]. The orientation distribution of water molecules that close to surface $(<3.63 \AA$ ) at (d) $\mathrm{U}=+0.29 \mathrm{~V}$ and (e) $\mathrm{U}=-0.46 \mathrm{~V}$ ( $\mathrm{x}$-axis is angle, $\mathrm{y}$-axis is distance to surface and $\mathrm{z}$ is the probability). The snapshots with atomic details of the interfaces are shown in (f) at $\mathrm{U}=$ $+0.29 \mathrm{~V}$ and $(\mathrm{g})$ at $\mathrm{U}=-0.46 \mathrm{~V}$. We highlight the first layer of water by plotting the van der Waals surface of oxygen as blue in transparent. The blacked dashed line shows the boundary of simulation cell. We highlight the water with $\mathrm{OH}$ parallel to the surface $\left(\mathrm{H}_{2} \mathrm{O}^{=}\right)$with colored stars.

The question now is the influence of water adsorption to HBE*. To predict the HBE*, we employed Widom insertion (WI) meth$\operatorname{od}^{20}$ (the details of the WI calculations are in the SI) to calculate the free energies of hydrogen binding on the interface at $\mathrm{U}=$ $+0.29 \mathrm{~V},-0.01 \mathrm{~V},-0.10 \mathrm{~V},-0.33 \mathrm{~V}$ and $-0.46 \mathrm{~V}$. The obtained HBE* at different Us can be converted back to $\mathrm{pH}$ of $0.2,5.2,6.710 .7$ and 12.8 at $\mathrm{U}=0.3 \mathrm{~V}$ (RHE). Therefore, we can compare our calculated HBE* directly with the experimentally measured $\mathrm{pH}$ dependent HBE*. ${ }^{12}$ As shown in Figure 3, the predictions from QMMD well reproduce the increase of $\mathrm{HBE}^{*}$ as a function of $\mathrm{pH}$. The largest deviation between QMMD predictions and experiment is less than $0.05 \mathrm{eV}$, which is already within the accuracy of PBE calculations. The slope predicted from QMMD is $10 \mathrm{meV} / \mathrm{pH}$ 
(more details about data fitting is in SI), very close to 8 to 12 $\mathrm{meV} / \mathrm{pH}$ as measured experimentally. ${ }^{12}$ Thus, without postulating of cation or anion effects, ${ }^{21}$ it appears that water adsorption is the dominant cause of the $\mathrm{pH}$-dependent HBE*.

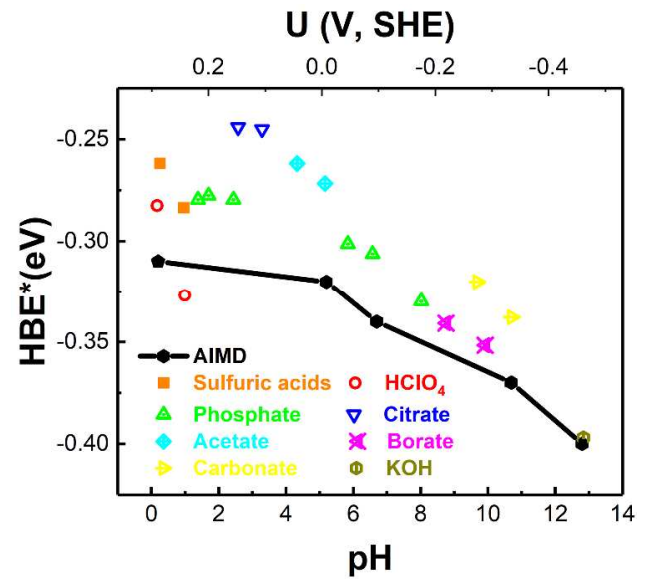

Figure. 3 comparison of apparent hydrogen binding energies (HBE*) between QMMD predictions (solid black lines with hexagons) and experiment data (scatter symbols) at $\mathrm{pH}$ ranging from 0.2 to 12.8 (bottom $\mathrm{x}$-axis) or $\mathrm{U}$ ranging from 0.29 to $-0.46 \mathrm{~V}$ (top $\mathrm{x}$-axis). The experimental data is from the work of Shen et al. ${ }^{12}$

The presence of $\mathrm{H}_{2} \mathrm{O}^{=}$could be potentially determined from experimental measurements, such as ambient pressure X-ray photoelectron spectroscopy (APXPS) ${ }^{22}$ and attenuated total reflectance infrared (ATR-IR) spectroscopy. We have calculated the O1s chemical shifts of various $\mathrm{H}_{2} \mathrm{O}$ molecules near the surface and found that the bulk water has $\mathrm{O} 1 \mathrm{~s}$ from $506.66 \mathrm{eV}$ to $507.36 \mathrm{eV}$, while the $\mathrm{O} 1 \mathrm{~s}$ for $\mathrm{H}_{2} \mathrm{O}^{=}$is $507.54 \mathrm{eV}$. Thus, we predicted $-0.18 \mathrm{eV}$ to $-0.88 \mathrm{eV}$ chemical shift of $\mathrm{O} 1 \mathrm{~s}$ as guidance to distinguish $\mathrm{H}_{2} \mathrm{O}^{=}$ in APXPS experiment. Meanwhile, $\mathrm{H}_{2} \mathrm{O}^{=}$also exhibits different rotation and vibration behavior as compared with bulk water. We employed Two-phase Thermodynamic (2PT) model to predict the density of state (DOS) of water from QMMD (as shown in Figure $\mathrm{S} 10){ }^{23}$ We observe that $\mathrm{H}_{2} \mathrm{O}^{=}$exhibits significant blue shifts in both rotation and vibration. For example, we predict $\sim 300$ wavenumbers blue shift of $\mathrm{H}-\mathrm{O}-\mathrm{H}$ bending mode. The entropy of $\mathrm{H}_{2} \mathrm{O}^{=}$from the $2 \mathrm{PT}$ calculation is $38.06 \mathrm{~J} / \mathrm{K}$, about $25 \%$ decrease than that of bulk water from the PBE-D3 prediction $(51.32 / \mathrm{K}){ }^{24}$ which indicates that $\mathrm{H}_{2} \mathrm{O}^{=}$is more active and could increase the kinetic of Volmer reaction and Heyrovsky reaction. ${ }^{25}$

In summary, we carried out full solvent in situ QMMD simulation to explicitly simulate the water/Pt (100) interface at $\mathrm{U}$ from $+0.29 \mathrm{~V}$ to $-0.46 \mathrm{~V}$, which are equivalent to $\mathrm{pH}$ from 0.2 to 12.8 at $\mathrm{U}=0.3 \mathrm{~V}$ (RHE). We found that Pt (100) electrode becomes more hydrophobic as $\mathrm{U}$ decreasing from $+0.29 \mathrm{~V}$ to $-0.46 \mathrm{~V}$, which is due to the negative charged $\mathrm{Pt}(100)$ tends to repel water adsorption. The decrease of water adsorption, in turn, increases hydrogen bonding within the monolayer, resulting in $0.13 \mathrm{eV}$ increase in HBE*. Assuming the linearly relationship between reaction energy difference and reaction energy barrier, a rough estimation is 153 times decrease in HER basing on Arrhenius equation. The slope of $\mathrm{pH}$-depended $\mathrm{HBE}^{*}$ predicted from QMMD is $10 \mathrm{meV} / \mathrm{pH}$, very close to the experimental observation of 8 to $12 \mathrm{meV} / \mathrm{pH}$. Thus, we conclude that water adsorption is the dominant cause of pH-dependent HBE*. From QMMD, we found that the change of binding leads to dramatic water reorientations which lead to a $-0.18 \mathrm{eV}$ to $-0.88 \mathrm{eV}$ change in $\mathrm{O} 1 \mathrm{~s}$ chemical shift, and significant blue shifts in surface water vibrations (for example, $\sim 300$ wavenumbers blue shift of $\mathrm{H}-\mathrm{O}-\mathrm{H}$ bending mode). These results show the importance of including explicit solvent in QM simulations to correctly describe electrochemical catalysis.
Thus, for HOR/HER catalysis design, instead of only relying on gas phase hydrogen binding calculations, it is equally important to consider the water adsorption or surface hydrophilicity which can be achieved by alloying or introducing hydrophilic surface groups (such as $\mathrm{OH}$ ).

\section{ASSOCIATED CONTENT}

\section{Supporting Information}

The Supporting Information is available free of charge on the ACS Publications website.

Detailed simulation methods (Reactive Force Field Simulation, Density Function Theory Calculation, Molecular Dynamics Simulation, Adjust Applied Voltage, Widom's Insertion, XPS Prediction, Two-Phase Thermodynamics Calculation), Interface Structure at $U=$ $0.90 \mathrm{~V}$, Simulations with $\mathrm{HCl}$ and $\mathrm{NaOH}$, Data Fitting and Density of State.

\section{AUTHOR INFORMATION}

\section{Corresponding Author}

wag@wag.caltech.edu

Notes

The authors declare no competing financial interests.

\section{ACKNOWLEDGMENT}

This work was initiated with support from National Science Foundation (CBET 1512759, program manager Robert McCabe) and completed with support from the Joint Center for Artificial Photosynthesis, a DOE Energy Innovation Hub, supported through the Office of Science of the U.S. Department of Energy under Award No. DE-SC0004993. This work used the Extreme Science and Engineering Discovery Environment (XSEDE) which is supported by National Science Foundation grant number ACI1053575.

\section{REFERENCES}

1. Gasteiger, H. A.; Marković, N. M., Science 2009, 324, 48-49.

2. Reier, T.; Oezaslan, M.; Strasser, P., ACS Catal. 2012, 2, 1765 -

1772 .

3. Durst, J.; Siebel, A.; Simon, C.; Hasche, F.; Herranz, J.; Gasteiger, H. A., Energy Environ. Sci. 2014, 7, 2255-2260.

4. Suntivich, J.; Gasteiger, H. A.; Yabuuchi, N.; Shao-Horn, Y., J. Electrochem. Soc. 2010, 157, B1263-B1268.

5. McCrory, C. C. L.; Jung, S.; Peters, J. C.; Jaramillo, T. F., J. Am. Chem. Soc. 2013, 135, 16977-16987.

6. Suntivich, J.; May, K. J.; Gasteiger, H. A.; Goodenough, J. B.; Shao-Horn, Y., Science 2011, 334, 1383-1385.

7. Strmcnik, D.; Lopes, P. P.; Genorio, B.; Stamenkovic, V. R.; Markovic, N. M., Nano Energy 2016, 29, 29-36.

8. Schouten, K. J. P.; van der Niet, M. J. T. C.; Koper, M. T. M., Phys. Chem. Chem. Phys. 2010, 12, 15217-15224.

9. Rossmeisl, J.; Chan, K.; Skúlason, E.; Björketun, M. E.; Tripkovic, V., Catal. Today 2016, 262, 36-40.

10. Zheng, J.; Sheng, W.; Zhuang, Z.; Xu, B.; Yan, Y., Sci. Adv. 2016, 2, e1501602.

11. Durst, J.; Simon, C.; Hasché, F.; Gasteiger, H. A., J. Electrochem. Soc. 2015, 162, F190-F203.

12. Sheng, W.; Zhuang, Z.; Gao, M.; Zheng, J.; Chen, J. G.; Yan, Y., Nat. Commun. 2015, 6, 5848.

13. Karlberg, G. S.; Jaramillo, T. F.; Skúlason, E.; Rossmeisl, J.; Bligaard, T.; Nørskov, J. K., Phys. Rev. Lett. 2007, 99, 126101.

14. Zheng, J.; Nash, J.; Xu, B.; Yan, Y., J. Electrochem. Soc. 2018, 165, H27-H29.

15. Domke, K.; Herrero, E.; Rodes, A.; Feliu, J. M., J. Electroanal. Chem. 2003, 552, 115-128.

16. Mathew, K.; Sundararaman, R.; Letchworth-Weaver, K.; Arias, T. A.; Hennig, R. G., J. Chem. Phys. 2014, 140, 084106. 
17. Jacob, T.; Muller, R. P.; Goddard, W. A., J. Phys. Chem. B 2003, 107, 9465-9476.

18. Cordero, B.; Gomez, V.; Platero-Prats, A. E.; Reves, M.; Echeverria, J.; Cremades, E.; Barragan, F.; Alvarez, S., Dalton Transactions 2008, 2832-2838.

19. Schwarz, K.; Xu, B.; Yan, Y.; Sundararaman, R., Phys. Chem. Chem. Phys. 2016, 18, 16216-16223.

20. Frenkel, D.; Smit, B., Chapter 7 - Free Energy Calculations. In Understanding Molecular Simulation (Second Edition), Academic Press: San Diego, 2002; pp 167-200.
21. McCrum, I. T.; Janik, M. J., J. Phys. Chem. C 2016, 120, 457471.

22. Ogasawara, H.; Brena, B.; Nordlund, D.; Nyberg, M.; Pelmenschikov, A.; Pettersson, L. G. M.; Nilsson, A., Phys. Rev. Lett. 2002, $89,276102$.

23. Lin, S.-T.; Maiti, P. K.; Goddard, W. A., J. Phys. Chem. B 2010, 114, 8191-8198.

24. Pascal, T. A.; Schärf, D.; Jung, Y.; Kühne, T. D., J. Chem. Phys. 2012, 137, 244507.

25. Ledezma-Yanez, I.; Wallace, W. D. Z.; Sebastián-Pascual, P.; Climent, V.; Feliu, J. M.; Koper, M. T. M., Nat. Energy 2017, 2, 17031.

\section{Insert Table of Contents artwork here}

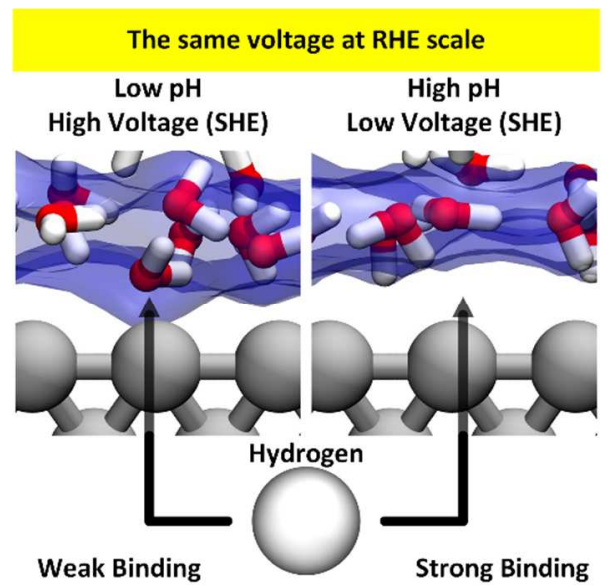

